\title{
Radioprotective Potential of Nigella Sativa Extract in Swiss Albino Mice Exposed to Whole Body $\gamma$-Radiation
}

\section{Ganesh Chandra Jagetia* and Ravikiran PB}

Department of Zoology, Mizoram University, India

*Corresponding author: Ganesh Chandra Jagetia, Professor, Department of Zoology, Mizoram University, Aizawl - 796 004, India, Tel: 091-389-2330724/2330227; Email: gc.jagetia@gmail.com

Rec date: Jun 25, 2014; Acc date: Aug 28, 2014; Pub date: Aug 30, 2014

Copyright: @ 2014 Jagetia GC, et al. This is an open-access article distributed under the terms of the Creative Commons Attribution License, which permits unrestricted use, distribution, and reproduction in any medium, provided the original author and source are credited

\begin{abstract}
The radioprotective activity of Nigella sativa extract (NSE) was ascertained by administering mice orally with 25 , $50,100,150,200,400$ or $500 \mathrm{mg} / \mathrm{kg} \mathrm{b}$. wt. of NSE, once daily for five consecutive days prior to $10 \mathrm{~Gy}$ Y-irradiation. One hour after the last administration of NSE on fifth day, the animals were whole body exposed to 10 Gy radiation. The exposure of animals to $10 \mathrm{~Gy}$ irradiation resulted in the death of all irradiated animals within 16 days postirradiation, whereas administration of mice with different doses of NSE reduced the radiation-induced mortality and increased the animal survival significantly $(p<0.05)$. The maximum number of survivors $(60 \%)$ was observed in the group of animals treated with $150 \mathrm{mg} / \mathrm{kg} \mathrm{NSE}$. A further increase in the NSE dose up to $500 \mathrm{mg} / \mathrm{kg}$ did not significantly elevate the animal survival when compared to $150 \mathrm{mg} / \mathrm{kg}$. Since maximum number of survivors was observed with $150 \mathrm{mg} / \mathrm{kg}$ of NSE, it was considered as an optimum dose for radioprotection and further experiments were performed using this dose. In another set of experiments the animals were administered with $150 \mathrm{mg} / \mathrm{kg} \mathrm{b}$. wt. of NSE orally once daily for five consecutive days before exposure to 7, 8, 9, 10 or 11 Gy y-radiation, where the animals were monitored daily up to thirty days post-irradiation for the development of symptoms of radiation sickness and mortality. Treatment of mice with NSE before irradiation delayed the onset of mortality and reduced the symptoms of radiation sickness when compared with the double distilled water (DDW) treated irradiated controls. The $\mathrm{LD}_{50 / 30}$ was found to be $8 \mathrm{~Gy}$ for DDW + irradiation group, whereas the NSE treatment increased $\mathrm{LD}_{50 / 30}$ up to 9.6 Gy with a dose reduction factor (DRF) of 1.2. The in vitro studies in cell free system revealed that NSE inhibited the generation of various free radicals including 2,2-diphenyl-2-picryl hydrazyl (DPPH), 3-ethyl benzothiazoline-6sulphonic acid $\left(\mathrm{ABTS}^{*}\right)$, hydroxyl $\left(\mathrm{OH}^{\circ}\right)$ and superoxide $\left(\mathrm{O}^{* *}\right)$ in a concentration dependent manner. The radioprotective effect of NSE may be due to free radical scavenging and increased antioxidant status.
\end{abstract}

Keywords: Mice; Nigella sativa; Free radicals; Radiation; Survival

\section{Introduction}

The discovery of ionizing radiations led to its widespread applications in various fields immediately. Ionizing radiations are regularly used in the diagnosis of various diseases, cancer treatment, nuclear power production, industry, research, weapon testing, nuclear warfare, and space explorations. These applications have led to increased exposure of humans to ionizing radiations advertently or inadvertently, which may result in the numerous deleterious health effects including cancer [1,2]. The longest sought and the most elusive goal in radiobiology research has been the development of potent multifunctional, multi target pharmacological agents, which are able to alleviate the ill effects of ionizing radiation on human health. It is fairly well established that the ionizing radiations interact with biological tissues mainly by indirect effect and induce cellular damage principally by the generation of free radicals in the cellular milieu [1]. These free radicals or reactive oxygen species (ROS) are generated by the interaction of ionizing radiations with aqueous milieu of cells that induce radiolysis of water [1]. The ROS thus generated are highly reactive and interact with molecular oxygen or various important biomolecules such as DNA, lipids, proteins and also with membranous structures of cells leading to oxidative stress, and subsequently disrupting the homeostasis between the pro-oxidants and antioxidants inside the microenvironment of the cell that causes damage to cell components [3].

With the realization of harmful effects of ionizing radiation, the need for the protection of mankind against the radiation induced deleterious effects was realized as early as 1949, when Patt and his coworkers tried cysteine, a sulphydryl group containing amino acid in rats to protect them against the deleterious effects of ionizing radiations and reported for the first time that cysteine protected the rats against the $\mathrm{X}$-irradiation-induced sickness and mortality [4]. Thereafter several sulphydryl containing compounds were tried; however, practical applicability of the majority of these synthetic compounds remained limited owing to their high toxicity at their optimum protective dose [5]. One of the best known radioprotector so far, the amifostine has been tired in clinical condition however; its widespread application remained limited because of its systemic toxicities and exorbitant cost. Over the years, although considerable advancement has been made in the field of radioprotection by screening various types of pharmacological agents for their radioprotective ability, none of these agents were found to be clinically useful [6,7].

An ideal radioprotector is a pharmacological agent, which is nontoxic, economically cheaper, and orally administrable and acts by multiple mechanisms [7]. A non-toxic radioprotector could be useful in occupational settings including defense, airline, military, research, dentistry, radiotherapy, nuclear medicine and/or nuclear accidents. A 
chemical radioprotector will be very useful in situations, where radioactivity is released accidentally in the environment eg. Three Mile Island, Chernobyland Goiania, and Fukushima. It may be also useful during air and/or space travel to protect humans from the deleterious effects of radiation associated with solar flares [2,6-8]. With the recent developments and increased accessibility of terrorists to improvised nuclear devices, threat of such attacks seems to be also imminent. This indicates the need to devise countermeasures to combat such situations and reduce the causalities to as minimum as possible. This could be achieved using effective pharmacological agents to protect humans [7]. The dietary agents have received little attention for their radioprotective activities. The dietary agents, if found radioprotective will be advantageous, as they are in regular use, economically cheaper and widely acceptable to humans and also do not have known untoward side effects [9].

Kalonji, the seeds of Nigella sativa Linn. (family: Ranunculaceae) have been used as a spice, condiment and food additive. The ancient system of medicine, the Ayurveda, is a Sanskrit word which means Science of Life (Ayur=life and veda=knowledge) and is the oldest human healthcare system of medicine. Kalonji has been used as a curative remedy for several disorders in the Ayurvedic system of medicine. It is effective in alopecia, asthma, mad dog bites, respiratory diseases, paralysis, palsy, migraine, amnesia, palpitation and diabetes mellitus [10,11]. Experimentally, kalonji has been reported to be antiasthmatic [12], anticancerous [13,14], anti-inflammatory [15], lactogogue and vermifuge [16]. It has been reported to be cytotoxic to multidrug resistant cells [17]. Nigella sativa has been reported to reduce cisplatin induced toxicity in rats [14]. The principle component of Nigella sativa, the thymoquinone has been reported to be hepatoprotective [18]. Kalonji has also been reported to inhibit histamine release in mast cells [19]. However the radioprotective activity of kalonji has not been yet studied. Therefore, the aim of the present study was to investigate the radioprotective potential of kalonji (Nigella sativa Linn.) in mice exposed to different doses of $\gamma$-radiation in a preclinical setting.

\section{Materials and Methods}

\section{Chemicals}

2,2-diphenyl-2-picryl hydrazyl (DPPH), sodium nitroprusside, Greiss reagent, 2,2-azino-bis(3-ethyl benzothiazoline-6-sulphonic acid) diammonium salt (ABTS) glutathione, chloro-2,4dinitrobenzene (CDNB), 5,5-dithiobis-2-nitrobenzoic acid (DTNB), trichloroacetic acid (TCA), thiobarbituric acid (TBA) and fetal calf serum (FCM) were purchased from Sigma Chemical Co. (St. Louis, MO, USA). The other chemicals such as absolute alcohol, dimethyl sulphoxide (DMSO), ethylene diamine tetraacetic acid (EDTA), sodium bicarbonate, sodium chloride, potassium hydrogen phosphate, disodium hydrogen phosphate, potassium chloride and hydrochloric acid were purchased from Merck India Ltd; Mumbai.

\section{Collection of Plant material and extraction}

The dried seeds of kalonji, Nigella sativa Linn. (family: Ranunculaceae) were commercially procured, identified and authenticated by Dr. P. K. Rajgopal, Taxonomist, Department of Botany, Mahatma Gandhi Memorial College, Udupi, India. The powdered material of Nigella sativa (NS) was sequentially extracted in a Soxhlet apparatus using petroleum ether $\left(60^{\circ} \mathrm{C}\right)$, chloroform and finally, the chloroform free marc was extracted in methanol. The methanol extract of NS was concentrated under reduced pressure and freeze dried. The dried methanol extract was stored at $-70^{\circ} \mathrm{C}$ until use. Henceforth the Nigella sativa extract will be referred as NSE throughout the manuscript.

\section{Animals}

The care of animals and handling were done according to the guidelines issued by the World Health Organization, Geneva, Switzerland and the INSA (Indian National Science Academy, New Delhi, India). Usually, six to eight weeks old Swiss albino mice weighing 22 to $24 \mathrm{~g}$ of either sex were selected from an inbred colony maintained under the controlled conditions of temperature $\left(23 \pm 2^{\circ} \mathrm{C}\right)$, humidity $(50 \pm 5 \%)$ and $12 \mathrm{~h}$ of light and dark cycle, respectively. The animals had free access to the sterile food and water, five animals were housed in a polypropylene cage containing sterile paddy husk (procured locally) as bedding throughout the experiment. The study was approved by the Institutional Animal Ethical Committee of Manipal University, Manipal, where the entire study was carried out.

\section{Mode of administration}

The NSE was freshly dissolved in double distilled water (DDW) and administered orally using an oral gavage.

\section{Experimental design}

The radioprotective activity of NSE was determined by performing the following experiments:-

\section{Maximum tolerated dose (MTD)}

The acute toxicity of NSE was determined according to the method Prieur et al., [17] with minor modifications. Briefly, mice weighing 25-35 g were fasted for $18 \mathrm{~h}$ by withdrawing food and water. The fasted animals were divided into two groups of 10 each. Each group of animals was administered p.o. with a single dose of 500, 1000, 2000, 3000 , and $5000 \mathrm{mg} / \mathrm{kg}$ b. wt. of NSE. The animals were provided with food and water immediately after the drug administration. The animals were monitored carefully and continuously for the first hour and thereafter for a period of $4 \mathrm{~h}$ at an interval of every $30 \mathrm{~min}$ and subsequent observations were made at 24,48 and $72 \mathrm{~h}$ and until 14 days post- drug treatment. $\mathrm{LD}_{50}$ was calculated using the probit analysis as described [18].

\section{Radioprotective effect}

The radioprotective effect of NSE was determined by dividing the animals into the following groups:-

DDW + irradiation: The animals of this group were administered with $0.1 \mathrm{ml} / \mathrm{kg}$ b. wt. of double distilled water (DDW).

NSE+irradiation: This group of animals was administered with NSE orally for five consecutive days before radiation exposure.

\section{Irradiation}

The prostate and immobilized animals, restrained in a specially designed well-ventilated acrylic box were wholebody exposed to $\gamma$ radiation from a ${ }^{60} \mathrm{Co}$ gamma teletherapy source (Theratron, Atomic Energy Agency, Canada) at the Shirdi Sai Baba Cancer Hospital, Manipal, at a dose rate of $1.33 \mathrm{~Gy} / \mathrm{min}$ in a field size of $25 \times 25 \mathrm{~cm}^{2}$ and at a distance (SSD) of $57.8 \mathrm{~cm}$. 


\section{Optimum dosing schedule}

A separate experiment was performed to select the optimum NSE administration schedule. The animals were divided into two groups of 10 each, where grouping and other conditions were essentially similar to that described in experimental design section. The animals were administered with $150 \mathrm{mg} / \mathrm{kg}$ b. wt. of NSE p.o. once daily for one (one hour before irradiation), three, five or seven consecutive days before exposure to $10 \mathrm{~Gy}$ of $\gamma$-radiation. Ten animals were used for each schedule of administration and a total of 50 animals were used for the whole experiment.

\section{Administration route selection}

Another experiment was conducted to select the best route of administration, where the animals were divided into two groups of 10 each. The grouping and other conditions were essentially similar to that described earlier. The most effective route of NSE administration was determined by administering mice with $150 \mathrm{mg} / \mathrm{kg}$ of NSE through different routes including intraperitoneal (i.p), intramuscular (i.m) or oral (p.o.) once daily for five consecutive days. One hour after the last administration on fifth day, the animals were exposed to $10 \mathrm{~Gy}$ of $\gamma$ - radiation. Ten animals were used for each route of administration and a total of 30 animals were used for the whole experiment.

\section{Optimum dose selection}

The optimum radioprotective dose of NSE was selected by conducting a separate experiment, where the animals were divided into two groups of 10 each as described above and administered with $0,25,50,100,150,200,300$ or $500 \mathrm{mg} / \mathrm{kg}$ b. wt. of NSE orally once daily for five consecutive days. One hour after the last administration on day fifth, the animals were exposed to $10 \mathrm{~Gy}$ of $\gamma$-radiation [19].

\section{Radioprotective effect}

An another experiment was conducted to determine the radioprotective activity of NSE where the animals were divided into two groups as described in section 2.5.2, except that the animals were administered with $150 \mathrm{mg} / \mathrm{kg}$ b. wt. of NSE for five consecutive days before exposure to 7, 8, 9, 10 or $11 \mathrm{~Gy}$ of $\gamma$-radiation. A total of 120 animals were used for this experiment.

The dose reduction factor (DRF) was calculated according to the methods as follows:

$$
\mathrm{DRF}=\frac{\mathrm{LD} 50 \text { of the NSE }+ \text { irradiation group }}{\mathrm{LD} 50 \text { of the DDW }+ \text { irradiation group }}
$$

\section{Estimation of Free radical scavenging activity}

The free radical scavenging ability of NSE was determined in cell free system in vitro for the following radical species:

\section{DPPH radical}

The effect of NSE on the inhibition of DPPH radical was estimated according to the method of Mensor et al., where an antioxidant reacts with the stable DPPH radical and converts it into 1,1-diphenyl-2picryl hydrazine. The ability to scavenge the stable DPPH radicals is measured as a decrease in the absorbance at $517 \mathrm{~nm}$. Aliquots containing various concentrations of NSE (10-120 $\mu \mathrm{g})$ in a final volume of $2 \mathrm{ml}$ were mixed with $2 \mathrm{ml}$ of $0.05 \mathrm{mM} \mathrm{DPPH}$ (in methanol). DPPH $(2 \mathrm{ml})$ with an equal amount of PBS served as control. The reaction mixture was incubated at $37^{\circ} \mathrm{C}$ for 20 minutes and the optical density (OD) was measured at $\lambda=517 \mathrm{~nm}$ using spectrophotometer. The DPPH radical scavenging activity was calculated as follows:-

$$
\% \text { Scavenging }[\mathrm{DPPH}]=[(\mathrm{A} 0-\mathrm{A} 1) / \mathrm{A} 0] \times 100
$$

Where A0 is the absorbance of the control and A1 is the absorbance in the presence of the samples and standard.

\section{Hydroxyl radical}

Hydroxyl radical scavenging assay was performed by the oxidation of deoxyribose as described by Halliwell et al. [22]. The $\mathrm{OH} \bullet$ were generated by Fenton reaction in Fe3+- EDTA-ascorbate- $\mathrm{H} 2 \mathrm{O} 2$ system. The degradation of deoxyribose by $\mathrm{OH} \bullet$ was estimated by measuring the thiobarbituric acid reactive substances (TBARS). Briefly, the reaction mixture contained ascorbic acid $(50 \mathrm{mM})$, EDTA $(2 \mathrm{mM})$, $\mathrm{H} 2 \mathrm{O} 2(1.42 \mathrm{mM})$, deoxyribose $(2.8 \mathrm{mM})$ and various concentrations of NSE in a final volume of $1.0 \mathrm{ml}$. The reaction mixture was incubated at $37^{\circ} \mathrm{C}$ for 30 minutes, followed by the addition of $1 \mathrm{ml}$ of $5 \%$ trichloroacetic acid (TCA) and $1 \mathrm{ml}$ of thiobarbituric acid (TBA), and heated in a water bath at $75^{\circ} \mathrm{C}$ for 30 minutes and cooled. The reaction mixture without NSE served as control. The absorbance was read at $534 \mathrm{~nm}$ using UV-VIS spectrophotometer (Shimadzu UV-260, Shimadzu Corp, Tokyo, Japan). Percent inhibition was calculated by the following equation:-

$$
\% \text { Inhibition }=[(\mathrm{A} 0-\mathrm{A} 1) / \mathrm{A} 0] \times 100
$$

Where A0 is the absorbance of the control and A1 is the absorbance in the presence of the samples and standard.

\section{Superoxide radical}

Superoxide scavenging activity of NSE was performed by the photooxidation of riboflavin according to the method of Hyland et al. [23]. The $3 \mathrm{ml}$ of reaction mixture, contained $20 \mathrm{mM}$ phosphate buffer, $100 \mathrm{mM}$ EDTA-sodium cyanide, $2 \mathrm{mM}$ of riboflavin, $75 \mu \mathrm{M}$ nitrobluetetrazolium and various concentrations of NSE. The control consisted of reaction mixture without NSE. The test samples along with control were illuminated under incandescent light for 20 minutes and the absorbance was recorded at $513 \mathrm{~nm}$. The percentage inhibition of superoxide anion generation was calculated using the following formula:-

$$
\% \text { Inhibition }=[(\mathrm{A} 0-\mathrm{A} 1) / \mathrm{A} 0] \times 100
$$

Where $\mathrm{A} 0$ is the absorbance of the control and A1 is the absorbance in the presence of the samples and standard.

\section{ABTS radical}

ABTS diammonium salt radical cation decolorisation test was performed using spectrophotometric method described by Miller et al. [24]. The ABTS reacts with potassium persulphate to produce the ABTS $\bullet+$ radical cation, a blue green chromogen. In the presence of antioxidant, the colored radical is converted back to colorless ABTS. Various concentrations of NSE $(10-120 \mu \mathrm{g})$ in a final volume of $1 \mathrm{ml}$ of PBS were mixed with $1 \mathrm{ml}$ of ABTS working solution. ABTS working solution with equal volume of PBS served as control. The reaction mixture was incubated at room temperature $\left(28^{\circ} \mathrm{C}\right)$ for 30 minutes and the absorbance was measured at $734 \mathrm{~nm}$. 
All the experiments were performed thrice and test of homogeneity was applied to find out variation among each experiment if any. The data of each experiment did not differ significantly from one another and hence, all the data have been combined and means calculated.

\section{Statistical analysis}

All data are expressed as Mean \pm SEM (Standard Error of Mean). The significance between different groups was determined by MantelCox Log Rank test, except free radical estimations, where statistical significance was determined by the Students ' $t$ ' test. A p value of $<0.05$ was considered as significant.

\section{Results}

The results are expressed as mean \pm SEM (Standard Error of the Mean) in Table 1 and Figures 1-7.

\section{Maximum tolerated dose (MTD)}

Administration of 500 to $1000 \mathrm{mg} / \mathrm{kg}$ b. wt. NSE did not show any adverse clinical signs and symptoms of toxicity up to day 14 post-drug treatment. Similarly, the body weights also remained unaltered in the animals treated with NSE when compared with the DDW treated control group. A further increase in the NSE dose resulted in a corresponding decrease in the animal survival and an administration of $2000 \mathrm{mg} / \mathrm{kg} \mathrm{b}$. wt. NSE resulted in a $50 \%$ reduction in the animal survival [Figure 1]. When the NSE dose was increased up to 3000 $\mathrm{mg} / \mathrm{kg}$ b. wt. the animal survival reduced up to $30 \%$ leading to a mortality of $70 \%$ and no animals survived when the NSE dose was further raised up to $5000 \mathrm{mg} / \mathrm{kg}$ b. wt. [Table 1]. The $\mathrm{LD}_{50(14)}$ was determined by probit analysis as described by Litchfield and Wilcoxon was found to be $2000 \mathrm{mg} / \mathrm{kg}$ b. wt. NSE [Table 1 and Figure 1].

\begin{tabular}{|l|l|l|l|}
\hline $\begin{array}{l}\text { NSE dose (mg/ } \\
\text { kg.b.wt.) }\end{array}$ & Mortality (\%) & Corrected (\%) & Probit values \\
\hline 500 & 0 & 2.5 & 3.04 \\
\hline 1000 & 00 & 2.5 & 3.04 \\
\hline 2000 & 50 & 50 & 4.75 \\
\hline 3000 & 70 & 70 & 5.52 \\
\hline 5000 & 100 & 97.5 & 6.96 \\
\hline LD50(14) value = 2000 mg/kg b.wt.
\end{tabular}

Table 1: Acute toxicity of oral administration of NSE in Swiss albino mice

\section{Optimum dosing schedule}

The optimum dosing schedule was determined by orally administering the animals with $150 \mathrm{mg} / \mathrm{kg}$ NSE once daily for one, three, or five consecutive days before $10 \mathrm{~Gy}$ irradiation and monitoring the animals for 30 days post-irradiation. A greatest number of animals receiving the oral administration of $150 \mathrm{mg} / \mathrm{kg}$ NSE for five days survived at day 30 post-irradiation, when compared to other administration schedules i.e. 1, 3 and 5 days [Figure 2]. Therefore, administration of NSE once daily for five consecutive days before irradiation was considered the best and further studies were carried out using this regimen.

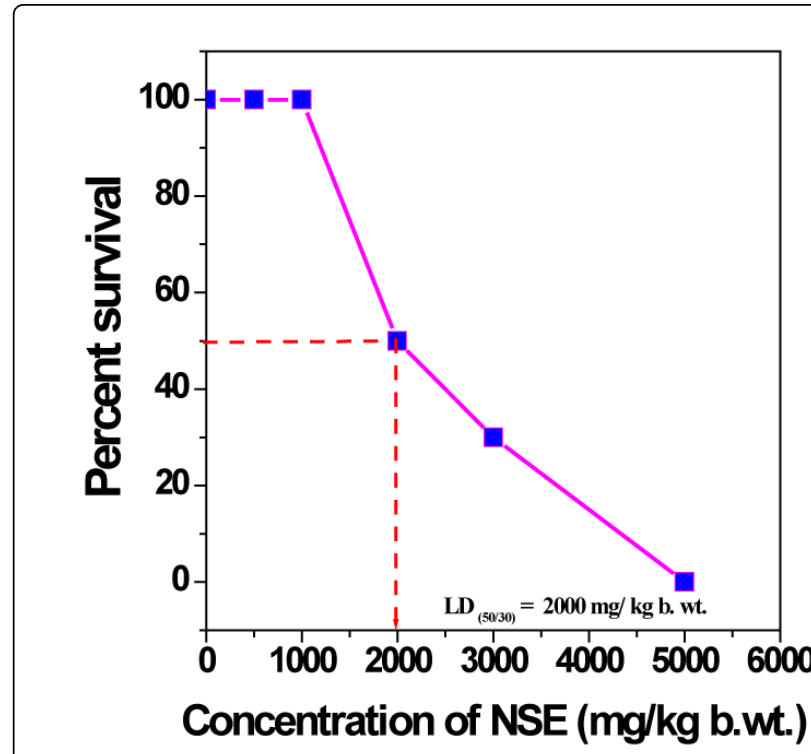

Figure 1: Acute toxicity of various doses of NSE after oral administration in Swiss albino mice. $\mathrm{LD}_{50}(14)$ value $=2000 \mathrm{mg} / \mathrm{kg} \mathrm{b}$. wt

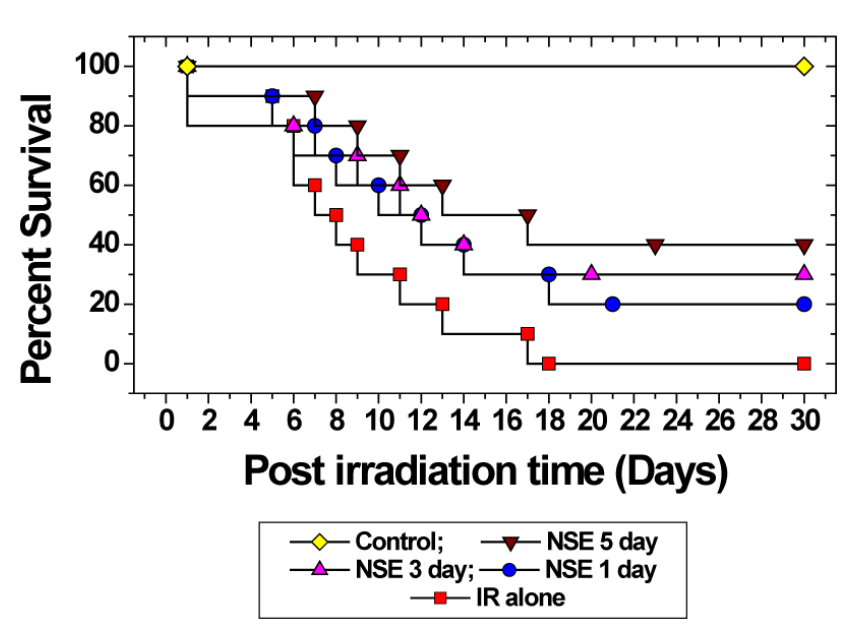

Figure 2: Effect of various dosing schedules of $150 \mathrm{mg} / \mathrm{kg}$ b. wt. NSE pre-treatment on the survival of mice exposed to $10 \mathrm{~Gy}$ of $\gamma$ radiation

\section{Administration route}

The administration of $150 \mathrm{mg} / \mathrm{kg}$ NSE, once daily, consecutively for five days by oral (po), intraperitoneal (ip) or intramuscular (im) route before irradiation to $10 \mathrm{~Gy}$ showed an increase in 30 day survival of mice. The analysis of thirty-day survival revealed that the optimum radioprotective activity was observed when the drug was administered through oral route rather than through ip or im route, where $40 \%$ animals survived after 30 days post irradiation than the other routes of administration [Figure 3]. 
Page 5 of 9

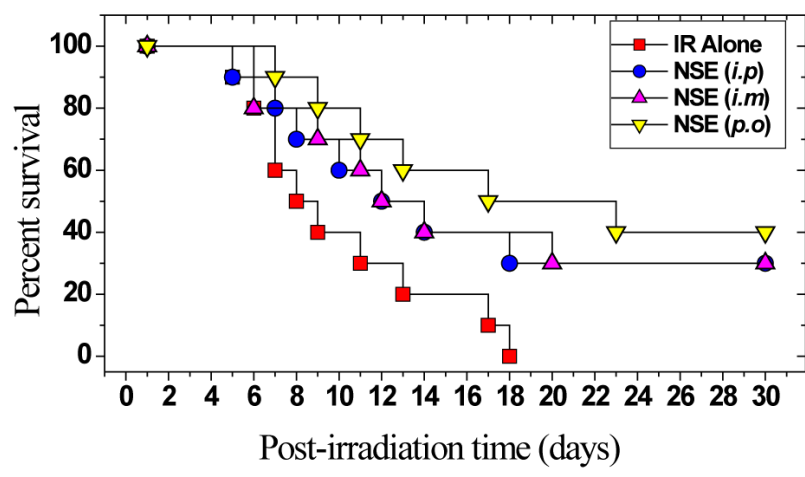

Figure 3: Effect of different routes of administration of $150 \mathrm{mg} / \mathrm{kg}$ b. wt. NSE on the Kaplan Meir's estimate of the survival of mice exposed to $10 \mathrm{~Gy}$ of $\gamma$-radiation

\section{Optimum dose}

The optimum radioprotective dose was determined by injecting different doses of NSE before whole-body exposure to 10 Gy $\gamma$ radiation. Oral administration of $500 \mathrm{mg} / \mathrm{kg}$ of NSE $\left(1 / 4 \mathrm{of} \mathrm{LD}_{50}\right)$ alone for five consecutive days did not cause any drug induced mortality up to 30 days. Exposure of animals to 10 Gy $\gamma$-irradiation resulted in a decline in the animal survival and the first death was observed on day 3 and majority of the animals died by 16 days post-irradiation in the $\mathrm{DDW}+10 \mathrm{~Gy}$ irradiation group. Administration of mice with various doses of NSE for five consecutive days before $10 \mathrm{~Gy}$ irradiation reduced the radiation-induced mortality. The administration of animals with different doses of NSE before $10 \mathrm{~Gy}$ irradiation increased the survival in a dose dependent manner up to $150 \mathrm{mg} / \mathrm{kg}$ NSE, where $40 \%$ animals survived as against nil in the DDW +10 Gy irradiation group. The administration of 50, 100, 200 and $400 \mathrm{mg} / \mathrm{kg}$ NSE to mice resulted in a $30 \%$ animal survival, whereas treatment of animals with 25 and $500 \mathrm{mg} / \mathrm{kg}$ NSE before 10 Gy irradiation resulted in $20 \%$ survival as against no survivors for $10 \mathrm{~Gy}$ alone at the end of 30 days after irradiation [Figure 4]. Animal survival increased significantly (p $<0.05$ ) for all doses of NSE treated groups when compared to the DDW-treated group, except for 25 and $500 \mathrm{mg} / \mathrm{kg}$ b. wt. NSE, where this increase was non-significant. Since a maximum survival was observed in the animals treated with $150 \mathrm{mg} / \mathrm{kg}$ of NSE before $10 \mathrm{~Gy}$ irradiation, it was considered as an optimum dose for radioprotection and further experiments were performed using this dose.

\section{Radiation Protection}

The radioprotective activity of NSE was determined by administering animals with $150 \mathrm{mg} / \mathrm{kg}$ of NSE orally once daily for five consecutive days before whole-body exposure to $0-11$ Gy of $\gamma$ radiation. Irradiation resulted in a dose-dependent decline in the animal survival, where the first mortality was observed on day 4 postirradiation in the group of animals receiving 9 Gy irradiation and all animals succumbed to death even before the end of 30th day after exposure to 10 and $11 \mathrm{~Gy}$ radiation in the DDW + irradiation group [Figure 5]. As $50 \%$ of the animals died after 30 days in the group receiving $8 \mathrm{~Gy}$ irradiation. The $\mathrm{LD}_{50 / 30}$ was found to be $8 \mathrm{~Gy}$ for DDW + irradiation group. Administration of $150 \mathrm{mg} / \mathrm{kg}$ NSE resulted in a significant elevation in the animal survival after irradiation to 10 and
11 Gy. Treatment of mice with $150 \mathrm{mg} / \mathrm{kg}$ NSE delayed the gastrointestinal deaths when compared to DDW + irradiation group, especially $9 \mathrm{~Gy}$, where it was delayed by 5 days [Figure 6]. This increased the LD50/30 up to 9.6 Gy resulting in an increase in the LD50/30 by $1.6 \mathrm{~Gy}$. The dose reduction factor (DRF) was found to be 1.2 [Figures 5 and 6].

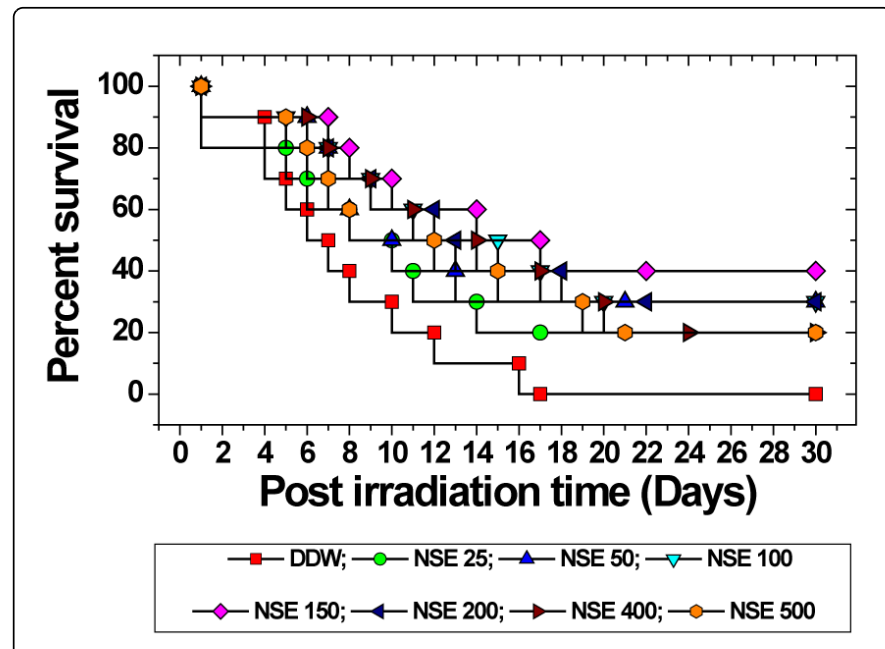

Figure 4: Kaplan Meir's estimate of the survival of mice treated with different doses of NSE p.o. before whole body exposure to $10 \mathrm{~Gy} \gamma$ radiation

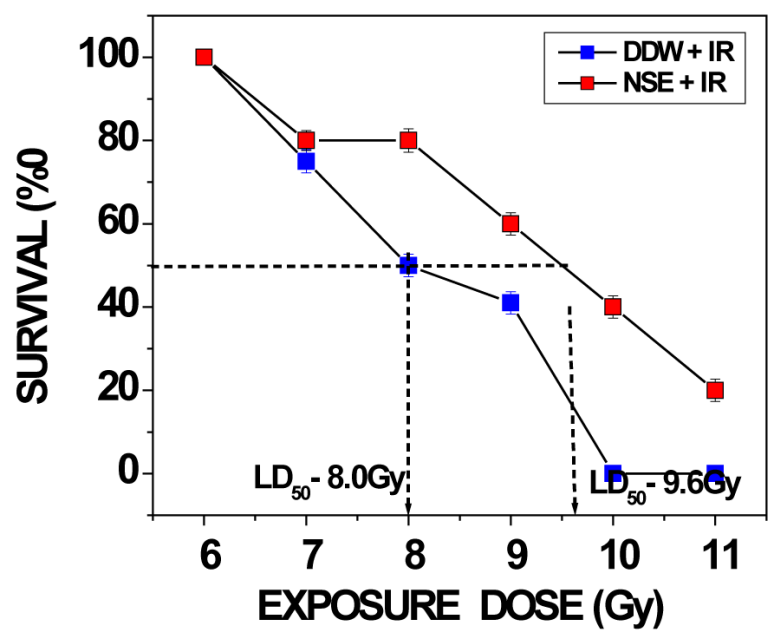

Figure 5: Radiation dose response curves for 30 day survival of mice after whole body $\gamma$-radiation with or without NSE $(150 \mathrm{mg} / \mathrm{kg} \mathrm{b}$. wt.) before exposure to 7-11 Gy

\section{Free radical scavenging activity}

\section{DPPH radical}

Introduction of different concentration in vitro resulted in a concentration dependent inhibition of DPPH radicals and a maximum reduction of $74 \%$ in DPPH radicals was observed at a concentration of $200 \mu \mathrm{g} / \mathrm{ml}$ [Figure 7a]. 

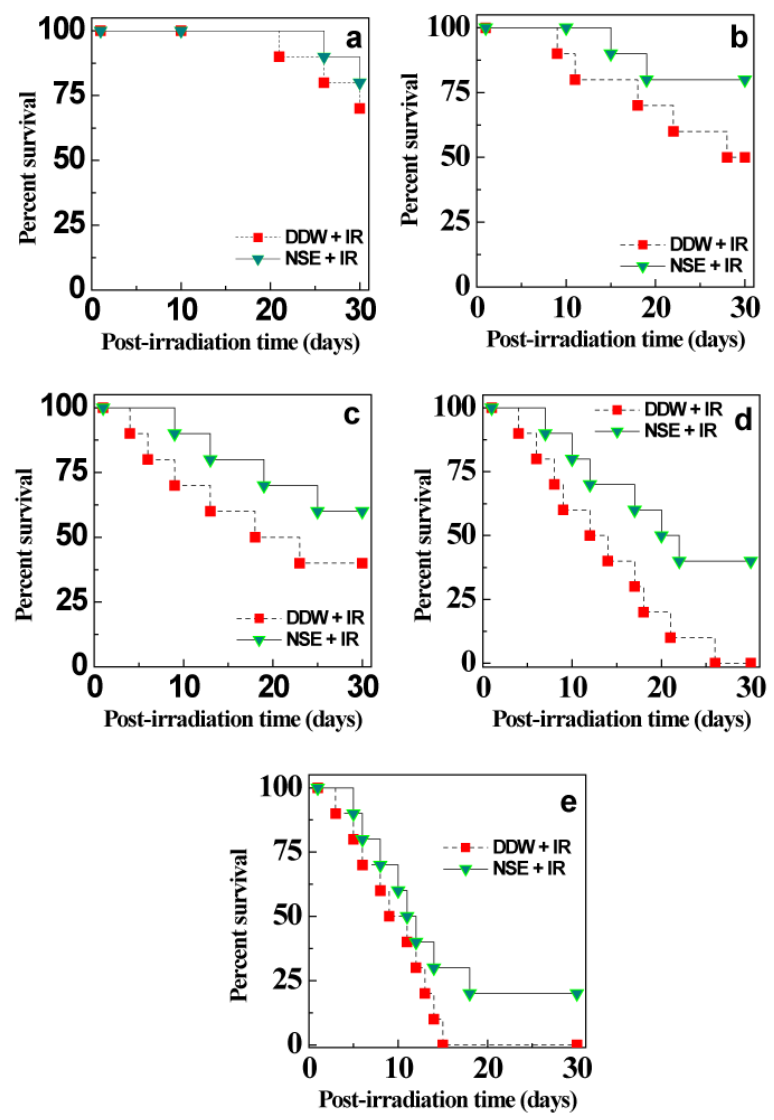

Figure 6: Kaplan-Meir's estimate of survival of mice treated with $150 \mathrm{mg} / \mathrm{kg}$ b. wt. of NSE before exposure to various doses of $\gamma$ radiation. a) 7 , b) 8 , c) 9 , d) 10 , e) 11 Gy radiation

\section{Hydroxyl radical}

NSE treatment significantly $(\mathrm{p}<0.05)$ inhibited 2-deoxyribose degradation in a concentration dependent manner [Figure $7 \mathrm{~b}$ ] and a maximum inhibition was observed at a concentration of $200 \mu \mathrm{g} / \mathrm{ml}$ $(75 \%)$ and a plateau thereafter [Figure $7 \mathrm{~b}$ ].

\section{Superoxide anion radical}

The generation of superoxide radicals was inhibited by NSE in a concentration dependent manner and a greatest inhibition was observed for $200 \mu \mathrm{g} / \mathrm{ml} \mathrm{NSE}$ where a $70 \%$ inhibition was reported for the superoxide radicals [Figure $7 \mathrm{c}$ ]

\section{ABTS radical}

The total antioxidant capacity of the NSE was estimated as the decolouration of ABTS $\bullet$, upon interaction with the NSE that suppressed the absorbance of the ABTS $\bullet+$ radical and the results are expressed as percent inhibition of absorbance as shown in Figure $7 \mathrm{~d}$. The ABTS cation radical was inhibited in a concentration dependent manner by NSE and a maximum inhibition was observed for 250 $\mu \mathrm{g} / \mathrm{ml}$ [Figure $7 \mathrm{~d}]$.
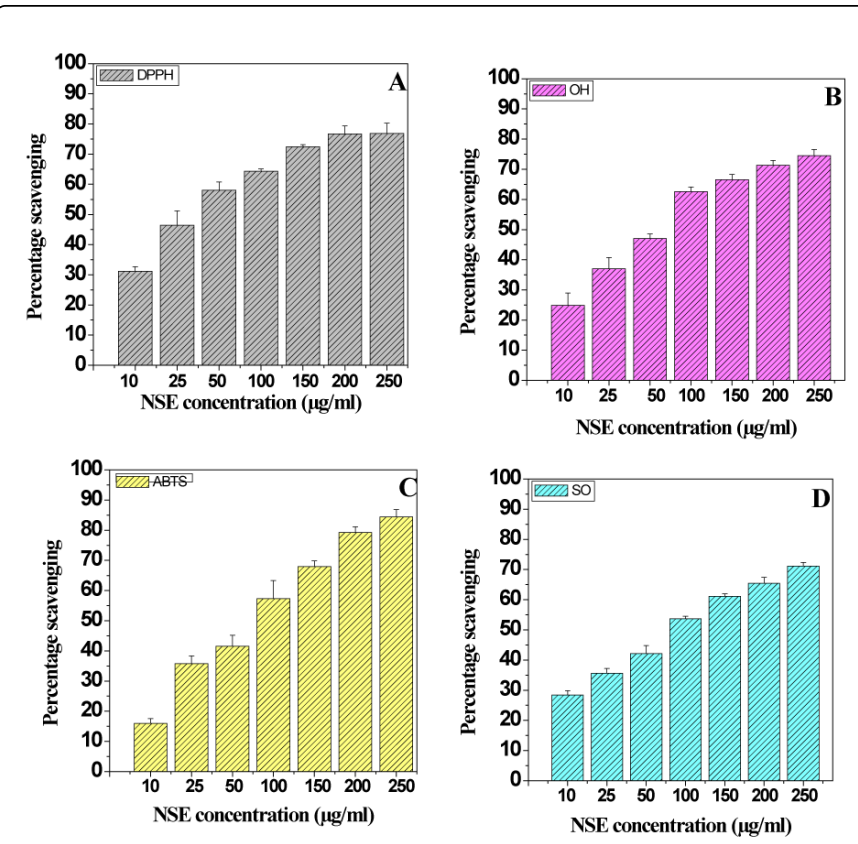

Figure 7: Effect of various concentrations of NSE on the scavenging of various free radicals generated in vitro. a) DPPH b) Hydroxyl c) ABTS $^{\bullet+}$ d) Superoxide anion

\section{Discussion}

Ionizing radiations induce a wide range of molecular damages, which subsequently lead to a spectrum of cellular responses causing cellular damage and cell death $[1,25]$. Numerous earlier studies on synthetic compounds have demonstrated their ability to protect against deleterious effects of ionizing radiation in various organisms. However, inherent toxicity of these agents at radioprotective concentrations precluded their clinical use [5], and more extensive pursuits for safe and efficacious radioprotectors have been underway since then. The increasing terror attacks and possibility of possession of improvised nuclear devices or dirty bomb in the hands of terrorist organization has reemphasized the need for an effective radioprotector, which is able to counter the deleterious effect of ionizing radiations. Several pharmacological agents have been screened for their radioprotective potential however; none meet the required properties that can be used as a countermeasure against the deleterious effects of ionizing radiations $[2,7,26]$. This implies that there is a continued need to search and screen newer pharmacological agents that are less toxic and highly effective as radioprotector/s. Therefore, the aim of the present study was to evaluate the radioprotective effect of Nigella sativa extract in mice exposed to different doses of $\gamma$-radiation.

The maximum tolerated dose of NSE was found to be $1000 \mathrm{mg}$, where no mortality was observed. With increasing dose the animals succumbed to death and 50\% survival was recorded for $2000 \mathrm{mg} / \mathrm{kg}$ NSE. Most of the plant extracts have been reported to have higher toxic doses earlier [27-34]. Dichloromethane extract of guduchi was found to have LD50 of $1.2 \mathrm{~g} / \mathrm{kg}$ b. wt. [35].

Administration of mice with different doses of NSE resulted in a dose dependent elevation in the animal survival after exposure to 10 
Gy up to a dose of $150 \mathrm{mg} / \mathrm{kg}$ NSE, where a maximum number of survivors were observed. The administration of higher doses of NSE before irradiation actually reduced the animal survival. A similar effect has been reported earlier with other radioprotectors including phytoceuticals [4,7,26-34]. These studies have demonstrated that radioprotective agents have an optimum dose and the decline in survival after this dose is due to the induction of toxic effects at higher doses [4,26-34]. A similar effect of NSE is discernible in the present study.

The irradiation of mice to different doses of $\gamma$-radiation caused a dose dependent reduction in the animal survival and the symptoms of radiation-induced sickness like reduction in the food and water intake, irritability lethargy, diarrhea, weight loss, emaciation and epilation within 3-5 days after $10 \mathrm{~Gy}$ irradiation is in good agreement with the earlier studies, where a similar effect has been observed [26-34,36,37]. The intestinal and bone marrow damage reduced the survival up to $40 \%$ within 10 days and the remaining animals succumbed to death within next 20 days is in corroboration with earlier studies, where a similar effect has been reported [26-34,36,37]. The ionizing radiations interact at cellular and molecular levels inducing damage to biologically important macromolecules such as DNA, RNA, proteins, lipids and carbohydrates of various organs. Usually molecular damages are expressed early, whereas the cellular and tissue damages may be expressed over a period of time depending on the cellular kinetics and radiation tolerance of the tissues. It is well established that the dividing cells are highly sensitive to the effect of ionizing radiations and the effect of whole body irradiation is mainly experienced by germinal epithelium, the gastrointestinal epithelium and the bone marrow progenitor cells, which are under constant renewal at a rapid rate. Since the germinal epithelium does not play any active role in the life supporting functions of the exposed individual, damage to it is inconsequential as far as organismal survival is concerned. In contrast, the gastrointestinal epithelium and the bone marrow progenitor cells are vital for the sustenance of life, and any damage or destruction of these cells will be felt by the whole organism. This will impair the normal physiological processes drastically leading to the death of animals depending upon the severity of damage suffered by these tissues. Despite the fact that the gastrointestinal epithelium is less sensitive than the bone marrow progenitor cells, its cell transit time is quick, and hence the radiation-induced damage is expressed earlier in the gastrointestinal epithelium than the hemopoietic system [37]. This is the reason that gastrointestinal syndrome is expressed earlier in the irradiated organisms than the bone marrow syndrome. In mice death within 10 days post-irradiation is due to the damage inflicted by radiation to the gastrointestinal epithelium and remaining deaths due to irradiation within 11 to 30 days post-irradiation is mainly due to hemopoietic damage inflicted by radiation to the bone marrow cells [26-34,36,37].

The NSE treatment before exposure to different doses of $\gamma$-radiation increased the animal survival by $30,20,40$ and $20 \%$ after exposure to $8,9,10$ and 11 Gy $\gamma$-radiation, respectively. A similar increase in the animal survival has been reported earlier when the animals were pretreated with other botanical extracts including Zinger officinale, Mentha arvensis, Aegle marmelos, Ageratum conzoides, Syzyzium cumini and Tinospora cordifolia before exposure to various doses of ionizing radiations [27-30,38,39]. Likewise, several other chemicals have been shown to elevate the survival of the animals after exposure to lethal doses of radiation $[4,40,41]$. Similarly, delta-tocotrienol, a vitamin $\mathrm{E}$ analogue and a strong antioxidant has been found to protect mice exposed to 9.2 Gy of $\gamma$-radiation [42]. The dose reduction factor
(DRF) is an indication of the extent of protection offered by any pharmacological agents. NSE treatment has elevated the LD50/30 up to 9.6 Gy resulting in an approximate increase of 1.6 Gy for NSE+ irradiation group as against the $8 \mathrm{~Gy}$ for DDW + irradiation group. The administration of NSE before irradiation resulted in a DRF of 1.2. Different agents have been reported to provide different DRF values and WR-2721 have been reported to give a DRF of $2.7[7,43]$.

The exact mechanism of action of radioprotection by NSE is not known. However, it may have used multiple putative mechanisms to provide protection to the animals against the radiation-induced sickness and mortality. The ionizing radiations interact with biomolecules by inducing various free radicals, which subsequently inflict damage to cells, tissues and organisms as a whole depending on the dose of radiation. The radioprotective action of NSE may have been mediated through scavenging of the radiation-induced primary free radicals and subsequent prevention of other reactive oxygen species. This contention is supported by our observations that NSE inhibited the generation of hydroxyl, superoxide and DPPH free radicals in the cell-free system. Similarly, it has also inhibited ABTS free radicals in vitro. A similar effect has been reported previously in essential oils obtained from $N$. sativa $[44,45]$. The other plausible mechanism of radioprotection by NSE may be increase in glutathione, antioxidant enzymes including glutathione peroxidase, glutathione-Stransferase, catalase and superoxide dismutase. NSE has been reported to upregulate the messenger RNA (mRNA) levels of glutathione-Stransferase [46]. As it has reduced the generation of free radicals NSE may have reduced the radiation-induced lipid peroxidation thereby by protecting cell damage. The NSE has been reported to scavenge lipid peroxidation in brain homogenate in vitro [44]. Although no effort has been made to study the molecular mechanisms of radioprotection by NSE, there is no reason to believe that NSE would have not employed the molecular pathways to exert its protective effect. The ionizing radiation induces DNA double strand breaks, which subsequently induce transactivation of NF- $\mathrm{\kappa B}$ and expression of COX-II in normal cells [47-49]. Therefore, blockage of transactivation of NF- $\kappa B$ and expression of COX-II may be one of the important molecular mechanisms of radioprotection by NSE [50]. Recently, Nfr2 gene has been identified to play an important role in antioxidant defense and ionizing radiation has been found to disrupt its activation [51]. The presence of NSE before irradiation may have inhibited this action of radiation against the $\mathrm{Nfr} 2$ gene keeping the antioxidant enzyme system in good shape leading to radioprotection [52].

The Nigella sativa seeds contain thymoquinone, nigellidine, $p$ cymene (rho), carvacrol, 4-terpineol, t-anethole (tau) and the sesquiterpene longifolene $[53,54]$. The observed radioprotective activity of NSE may be due to one of its components or as a concerted action of all these phytochemicals present in NSE.

In conclusion, administration of NSE protected mice against the radiation-induced sickness and mortality. The principle mechanism of radioprotection seems to be scavenging of various radiation-induced free radicals and increase in the activity of antioxidant enzymes. The molecular mechanisms that may have played important role in radioprotection by NSE include inhibition of radiation-induced transactivation of NF- $\kappa \mathrm{B}$, suppression of radiation-induced elevation in COX-II expression, inhibition of the radiation-induced decline in GST mRNA and Nfr2/HO gene, which is supported by various studies on the NSE. The radioprotective action of NSE may be mediated by the presence of various phytochemicals including thymoquinone, 
nigellidine, $p$-cymene (rho), carvacrol, 4-terpineol, $t$-anethole (tau) and the sesquiterpene longifolene.

\section{Acknowledgements}

We are thankful to Dr. M.S. Vidyasagar, Professor and Head, and Dr. J.G.R. Solomon, Department of Radiotherapy and Oncology, Kasturba Medical College Hospital, Manipal, for providing the necessary irradiation facilities and for dosimetric calculations, respectively. This work was carried out under a grant sanctioned to GCJ by the Council of Scientific and Industrial Research, Govt. of India, New Delhi.

\section{References}

1. Hall EJ (2000) Acute Effects of Total-Body Irradiation. "In: Radiobiology for the Radiologist" Lippincott Williams \& Wilkins, Philadelphia PA

2. Jagetia GC (2007) Radioprotection and radiosensitization by curcumin. Adv Exp Med Biol 595: 301-320.

3. O'Neill P, Fielden EM (1993) Primary radical process in DNA. Adv Radiat Biol 17: 53-120.

4. Patt HM, Tyree EB, Straube RL, Smith DE (1949) Cysteine protection against X-irradiation. Science 110: 213-214.

5. Sweeney TR (1979) A survey of compounds from the antiradiation drug development program of the U.S. Army Medical Research and development command. Government printing office, Washington DC publication 308-318.

6. Weiss JF, Landauer MR (2003) Protection against ionizing radiation by antioxidant nutrients and phytochemicals. Toxicology 89: 1-20.

7. Jagetia GC (2007) Radioprotective Potential of Plants and Herbs against the Effects of Ionizing Radiation. J Clin Biochem Nutr 40: 74-81.

8. Roberts L (1987) Radiation Accident Grips Goiania. Science 238: 1028-1031.

9. Jagetia GC, Venkatesha VA (2005) Effect of mangiferin on radiationinduced micronucleus formation in cultured human peripheral blood lymphocytes. Environ Mol Mutagen 46: 12-21.

10. Chopra RN, Nayar SL, Chopra IC (1956) Clossary of Indian Medicinal Plants. CSIR New Delhi India 175.

11. Warrier PK (1994) Indian Medicinal Plants : a compendium of 500 species Hyderabad Orient Longman 5: 245-247.

12. el-Tahir K, M Ashour, M Al-Harbi (1993) The cardiovascular actions of the volatile oil of the blackseed (Nigella sativa) in rats, elucidation of the mechanism of action. Gen. Pharmacol., 24: 1123-1131.

13. Salomi NJ, Nair SC, Jayawardhanan KK, Varghese CD, Panikkar KR (1992) Anti-tumor principles from Nigella sativa seeds. Cancer Lett 63: 41-46.

14. El Daly ES (1998) Protective effect of cysteine and vitamin E, Crocus sativus and Nigella sativa extracts on cisplatin-induced toxicity in rats. J Pharm Belg 53: 87-89

15. Houghton PJ, R Zarka, de las Heras B, JR Hoult (1995) Fixed oil of Nigella sativa and derived thymoquinone inhibit eicosanoid generation in leukocytes and membrane lipid peroxidation. Planta Med 61:33-36.

16. Ipor IB, Oyen LPA, de Guzman CC, Siemonsma JS (1999) Nigella sativa Lin: Plant Resources of South-East Asia No. 13: Spices. Backhuys Publisher, Leiden, The Netherlands 148-151.

17. Worthen DR, Ghosheh OA, Crooks PA (1998) The in vitro anti-tumor activity of some crude and purified components of blackseed, Nigella sativa L Anticancer Res 18: 1527-1532.

18. Daba MH, MS Abdel-Rahman (1998) Hepatoprotective activity of thymoquinone in isolated rat hepatocytes. Toxicol Lett 95: 23-29.

19. Chakravarty $N$ (1993) Inhibition of histamine release from mast cells by nigellone. Ann Allergy 70: 237-242.

20. Prieur DJ, Young DM, Davis RD, Cooney DA, Homan ER, et al. (1973) Procedures for preclinical toxicologic evaluation of cancer chemotherapeutic agents: protocols of the laboratory of toxicology. Cancer Chemother Rep 4: 1-28.

21. Mensor LL, Menezes FS, Leitao GG, Reis AS, dos Santos TC, et al. (2001) Screening of Brazilian plant extracts for antioxidant activity by the use of DPPH free radical method. Phytother Res 15: 127-130.

22. Halliwell B, Gutteridge JM, Aruoma OI (1987) The deoxyribose method: a simple "test-tube" assay for determination of rate constants for reactions of hydroxyl radicals. Anal Biochem 165: 215-219

23. Hyland K, Voisin E, Banoun H, Auclair C (1983) Superoxide dismutase assay using alkaline dimethylsulfoxide as superoxide anion-generating system. Anal Biochem 135: 280-287.

24. Miller NJ, Castelluccio C, Tijburg L, Rice-Evans C (1996) The antioxidant properties of theaflavins and their gallate esters--radical scavengers or metal chelators? FEBS Letters 392: 40-44.

25. Ryan JL (2012) Ionizing radiation: the good, the bad, and the ugly. J Invest Dermatol 132: 985-993.

26. Pandey BN, Kumar A, Tiwari P, Mishra KP (2010) Radiobiological basis in management of accidental radiation exposure Int J Radiat Biol 86: 613-35.

27. Jagetia GC, Baliga MS, Venkatesh P, Ulloor JN (2003) Influence of ginger rhizome (Zingiber officinale Rosc) on survival, glutathione and lipid peroxidation in mice after whole-body exposure to $\gamma$-radiation. Radiat Res 160: 584-592.

28. Jagetia GC, Shirwaikar A, Rao, SK, Bhilegaonkar PM, (2003) Evaluation of the radioprotective effect of Ageratum conyzoides Linn. extract in mice exposed to different doses of gamma radiation. J Pharm Pharmacol 8: 1151-1158.

29. Jagetia GC, Venkatesh P, Baliga MS (2004) Evaluation of the radioprotective effect of bael leaf (Aegle marmelos) extract in mice. Int J Radit Biol 4: 281-290.

30. Jagetia GC, Baliga MS, Venkatesh P (2005) Influence of seed extract of Syzygium cumini (Jamun) on mice exposed to different doses of $\gamma$ radiation. J Radiat Res 46: 59-65.

31. Jagetia GC, Baliga MS (2002) Cystone, an ayurvedic herbal drug imparts protection to the mice against the lethal effects of $\gamma$ - radiation: a preliminary study. Nahrung/Food 5: 332- 336.

32. Jagetia GC, Baliga MS (2003) Treatment of mice with a herbal preparation mentat protects against radiation-induced mortality. Phytother Res 8: 876-881.

33. Jagetia GC, Baliga MS (2004) Polyherbal extract of septilin protects mice against whole body lethal dose of gamma radiation. Phytother Res 18: 619-623.

34. Jagetia GC, Baliga MS (2004) Evaluation of the radioprotective action of geriforte in mice exposed to different doses of gamma-radiation. Am J Chinese Med 4: 551-567.

35. Jagetia GC, Nayak V, Vidhyasagar MS (2002) Enhancement of radiation effect by guduchi (Tinospora cordifolia) in HeLa cells. Pharmaceutical Biology 40: 179-188.

36. Jagetia GC, Ganapathi NG, Venkatesh P, Rao N, Baliga MS (2006)Evaluation of the radioprotective effect of Liv 52 in mice. Environmental and Molecular Mutagenesis 47: 490-502.

37. Bond VP, Fliedner T, Archambeau JO (1965) Mammalian Radiation Lethality. Academic Press New York USA

38. Tayagi S, Singh L, Devi MM, Goel HC, Rizvi MA (2009) Augmentation of Antioxidant Defense System by Tinospora cordifolia: Implications in Radiation Protection. J Complement Integrat Med 6: 36.

39. Jagetia GC, Baliga MS (2002) Influence of the leaf extract of Mentha arvensis Linn. (mint) on the survival of mice exposed to different doses of gamma radiation. Strahlenther Onkol 178: 91-98.

40. Ghosh SP, Perkins MW, Hieber K, Kulkarni S, Kao TC (2009) Radiation protection by a new chemical entity, Ex-Rad: efficacy and mechanisms. Radiat Res 171: 173-179

41. Kuntić VS, Stanković MB, Vuiić ZB, Brborić JS, Uskoković-Marković SM (2013) Radioprotectors - the evergreen topic. Chem Biodivers 10: 1791-1803. 
Citation: Jagetia GC, Ravikiran PB (2014) Radioprotective Potential of Nigella Sativa Extract in Swiss Albino Mice Exposed to Whole Body YRadiation. Altern Integr Med 3: 168. doi:10.4172/2327-5162.1000168

Page 9 of 9

42. Singh VK, Wise SY, Scott JR, Romaine PL, Newman VL, et al (2014) Radioprotective efficacy of delta-tocotrienol, a vitamin $\mathrm{E}$ isoform, is mediated through granulocyte colony-stimulating factor. Life Sci 98: 113-122.

43. Yuhas JM, Storer JB (1969) Chemoprotection against three modes of radiation death in the mouse. Int J Radiat Biol Relat Stud Phys Chem Med 15: 233-237.

44. Burits M, Bucar F (2000) Antioxidant activity of Nigella sativa essential oil. Phytotherapy Research 14: 323-328.

45. Abdel-Wahhab MA, Aly SE (2005) Antioxidant property of Nigella sativa (black cumin) and Syzygium aromaticum (clove) in rats during aflatoxicosis. Journal of Applied Toxicology. 25: 218-223.

46. El-Sayed WM (2011) Upregulation of Chemoprotective Enzymes and Glutathione by Nigella sativa(Black Seed) and Thymoquinone in CCl4Intoxicated Rats. Int J Toxicol 30: 707-714.

47. Meng A, Yu T, Chen G, Brown SA, Wang Y, et al (2003) Cellular origin of ionizing radiation-induced NF-kappaB activation in vivo and role of NF-kappaB in ionizingradiation-induced lymphocyte apoptosis. Int J Radiat Biol 79: 849-861.

48. Dong XR, Luo M, Fan L, Zhang T, Liu L (2010) Corilagin inhibits the double strand break-triggered NF-kappaB pathway in irradiated microglial cells. Int J Mol Med 25: 531-536.
49. Moore ED, Kooshki M, Metheny-Barlow LJ, Gallagher PE, Robbins ME (2013) Angiotensin-(1-7) prevents radiation-induced inflammation in rat primary astrocytes through regulation of MAP kinase signaling. Free Radic Biol Med 65: 1060-1068.

50. Kundu JK, Liu L, Shin JW, Surh YJ (2013) Thymoquinone inhibits phorbol ester-induced activation of NF- $\mathrm{\kappa B}$ and expression of COX-2, and induces expression of cytoprotective enzymes in mouse skin in vivo. Biochem Biophys Res Commun 438: 721-727.

51. Kim SB, Pandita RK, Eskiocak U, Ly P, Kaisani A, et al (2012) Targeting of Nrf2 induces DNA damage signaling and protects colonic epithelial cells from ionizing radiation. Proc Natl Acad Sci USA 109: 2949-2955

52. Ulu R, Doğukan A, Tuzcu M, Gürel A, Muqbil I, et al (2013) Modulation of Nrf2/HO-1 by Thymoquinone During Cisplatin-Induced Nephrotoxicity. Turk Neph Dial Transpl 22: 182-187

53. Ali BH, Blunden G (2003) Pharmacological and toxicological properties of Nigella sativa. Phytotherapy Research 17: 299-305.

54. Ali Z, Ferreira D, Carvalho P, Avery MA, Khan IA (2008) Nigellidine-4$\mathrm{O}$-sulfite, the first sulfated indazole-type alkaloid from the seeds of Nigella sativa. J Nat Prod 71: 1111-1112. 